\title{
COMPOSITION OF ENDOPHYTIC FUNGAL COMMUNITY ASSOCIATED WITH LEAVES OF MAIZE CULTIVATED IN SOUTH BRAZILIAN FIELD
}

\author{
VIVIAN J. SZILAGYI-ZECCHIN ${ }^{1 *}$, DOUGLAS ADAMOSKI ${ }^{2}$, \\ Renata Rodrigues GOMEs ${ }^{3}$, MARIANGEla Hungria ${ }^{4}$, Angela C. IKEDA ${ }^{2}$, \\ VANESSA KAVA-CORDEIRO ${ }^{2}$, CHIRLEI GLIENKE ${ }^{2}$ and \\ LYGIA V. GALLI-TERASAWA ${ }^{2}$ \\ ${ }^{1}$ Department of Plant Science and Crop Protection, Federal University of Paraná, \\ Curitiba, Brazil \\ ${ }^{2}$ Department of Genetics, Federal University of Paraná, Curitiba, Brazil \\ ${ }^{3}$ Department of Basic Pathology, Federal University of Paraná, Curitiba, Brazil \\ ${ }^{4}$ Soil Biotechnology Laboratory, Embrapa Soja, Londrina, Brazil
}

(Received: 3 September 2015; revised manuscript received: 13 April 2016; accepted: 6 September 2016)

The objective of this study was to conduct a survey about fungi associated with leaves from two different maize plant lineages and to analyze their microbiota diversity. Isolated fungi were identified by morphological analysis and molecular taxonomy was performed using ITS1-5.8S-ITS2 rDNA. About 27 fungi morphotypes were obtained, 15 of them were from the first maize lineage. About $86.7 \%$ of the individuals belonged to the Dothideomycetes class (Phoma sorghina, Epicocum nigrum, Cladosporium sp., Bipolaris zeicola, and Alternaria alternata complex) and $13.3 \%$ to the Sordariomycetes class (Diaporthe/Phomopsis sp. and Nigrospora sp.). This ratio was opposite in the other maize lineage with $25.0 \%$ of Dothideomycetes (E. nigrum and Pleosporales) and $75.0 \%$ of Sordariomycetes (Gibberella fujikuroi complex, Fusarium graminearum complex, Diaporthe/Phomopsis sp., and Nigrospora sp.). By concerning the analyses of morphological characteristics and molecular phylogeny, this study intended to identify the groups of saprophytic, phytopathogenic, and mycotoxin fungi, which differently co-inhabit leaf tissue of maize plants in both tested lineages.

Keywords: fungi, molecular phylogeny, microbiota, ITS1-5.8S-ITS2

*Corresponding author; E-mail: vivian.szilagyi@gmail.com 


\section{Introduction}

Maize (Zea mays L.) crop has a high economic impact on Brazilian agriculture. This is because it is a rising commodity on international market due to its extensive supply chain. Furthermore, it is essential to compose the crop rotation system [1].

Leaves represent one of the most dynamic interfaces of plants. Fungi inhabiting this tissue share the characteristics that allow them to grow and survive in a constantly biochemical changing environment. This constant change is mainly due to the different stages of plant development [2].

Endophytes are fungi growing inside plants without causing symptoms. Normally, this group is ubiquitous, and the associated plant species have few descriptions in the literature. There is a large biological diversity among endophytes, and it is not rare for some plant species to host more than 100 different endophytic species. In addition, different lifestyles occur among endophytic species, and the same endophytic fungi can be either pathogenic (those that cause diseases to plants) or harmless, depending on the host and its health [3]. Besides, some saprophytic fungi (those that obtain nutrients from organic matter of dead plants) found in senescent plants have been isolated as endophytes inhabiting healthy tissues [4]. These endophytic fungi behave as latent saprophytes and are asymptomatic and spatially restricted during the host development, but can grow and unrestrictedly reproduce when the host tissue ages or dies [5].

The mutual dependence between endophytic fungi and plants leads to desirable consequences, such as herbivory reduction, drought resistance increase, plant growth promotion, and insect and pathogenic fungi control [6].

However, fungi are the main microorganisms responsible for yield losses in maize grain production [7], causing seed rot, seedling death [8], and damage during grain storage [9]. Furthermore, if ingested, contaminated seeds can lead to severe poisoning [10].

It is known that interaction between microorganisms and their hosts can be influenced by several causes. As an example, the genetic diversity of symbionts; the ways they are acquired from environment and the ability of individuals to colonize hosts. In addition, direct and indirect interactions between the environment and the evolutionary history of each microorganism should be considered. Genomic architecture is involved in all these aspects and it is associated with pathogenicity or with other kinds of environment interaction (endophytes or saprophytes) [11].

This study aimed to lead a survey about genetic diversity of fungi associated with leaves from two lineages of maize plants, performing the analyses of morphological characteristics and molecular taxonomy. 


\section{Materials and Methods}

\section{Fungi isolation}

Leaf samples were collected from two maize plant lineages (L1 and L2) (Zea mays L.), cultivated in the same area. Lesions were observed in both lineages, L1 presented signs of Cercospora leaf spot, whose etiologic agent is Cercospora zeae-maydis and L2 presented typical lesion spots of Exserohilum turcicum. Leaves were collected when plants were in the phenological stage of grain filling and the lineages were cultivated at the experimental station of Semília Genetics and Breeding LTDA, Campo Largo, Paraná, Brazil. A direct planting system was used without crop rotation.

Fungi isolation was performed by washing the leaves in water and treating them with $70 \%$ ethanol (v/v) for $1 \mathrm{~min}, 3 \% \mathrm{NaClO}(\mathrm{v} / \mathrm{v})$ for $4 \mathrm{~min}, 70 \%$ ethanol $(\mathrm{v} / \mathrm{v})$ for $30 \mathrm{~s}$, followed by three consecutive washes in distilled water. Five fragments $(5-7 \mathrm{~mm})$ were incubated at $28{ }^{\circ} \mathrm{C}$ in Petri dishes containing Potato Dextrose Agar (PDA) medium, supplemented with tetracycline $(100 \mathrm{mg} / \mathrm{mL})$.

\section{Morphological characterization}

Isolated fungi were grouped into morphotypes according to their micromorphological characteristics (reproductive structures), analyzed by microculture technique and macromorphological characteristics (e.g., colony color and structure and growth rate). They were incubated on Tomato Juice Extract Agar and PDA culture media, at $28{ }^{\circ} \mathrm{C}$ during 7,14 , and 21 days. From each colony, a lamina was prepared containing the fungus stained by cotton lactophenol blue. Each lamina was visualized under optical microscopy and, when possible, morphological features were compared with taxonomic patterns [12].

The isolated fungi are classified in the collection of microorganisms from the Microorganisms Genetics Laboratory, Federal University of Paraná, Curitiba, Paraná, Brazil. Fungi colonies are maintained into inclined tubes containing PDA medium, kept at $4{ }^{\circ} \mathrm{C}$. Mycelia are also stored in distilled water at room temperature.

\section{Genomic DNA extraction and ITS1-5.8S-ITS2 rDNA sequencing}

One fungus colony of each morphotype was selected for genomic DNA extraction. This extraction was performed using the Microbial ultraclean DNA Isolation Kit (MoBio ${ }^{\circledR}$, Carlsbad, CA, USA), according to the manufacturer's instructions, and DNA resuspended in $20 \mu \mathrm{L}$ of ultrapure water. Its integrity was 
verified by electrophoresis on agarose gel $0.8 \%(w / v)$, stained with GelRed ${ }^{\mathrm{TM}}$ (Biotium, USA), observed in an UV transilluminator (Ultraviolet Benchtop transilluminators) and photo-documented (Program Digidoc it). DNA quantification and purity were assessed by the spectrophotometer NanoDrop ${ }^{\circledR} 2000$ (Thermo Scientific, Wilmington, USA).

Amplification of ITS1-5.8S-ITS2 rDNA was performed by polymerase chain reaction (PCR) using primersV9G [13] and ITS4 [14] with 10 ng of DNA, $1 \mathrm{X}$ PCR buffer, $0.5 \mathrm{U}$ Taq polymerase, $0.1 \mathrm{mM}$ of each primer $(1.25 \mathrm{pmol} /$ reaction), $0.2 \mathrm{mM}$ of each $\mathrm{dNTP}, 1.5 \mathrm{mM} \mathrm{MgCl}_{2}$, and $12.5 \mu \mathrm{L}$ final volume. Initial DNA denaturation was at $94{ }^{\circ} \mathrm{C}$ for $2 \mathrm{~min}$, followed by 35 cycles of $30 \mathrm{~s}$ at $94{ }^{\circ} \mathrm{C}$, $1 \mathrm{~min}$ at $55^{\circ} \mathrm{C}, 1 \mathrm{~min}$ at $72{ }^{\circ} \mathrm{C}$, and final extension at $72{ }^{\circ} \mathrm{C}$ for $3 \mathrm{~min}$. DNA fragment integrity was verified as described above on agarose gel $1.5 \%(\mathrm{w} / \mathrm{v})$. Purification with ammonium acetate $7.5 \mathrm{M}$ was performed according to Menna et al. [15]. Ultrapure water was used to resuspend PCR products and their quantification and purity were measured by spectrophotometry as described above, adjusting final concentration to $10 \mathrm{ng} / \mu \mathrm{L}$.

Sequencing reaction was performed using $50 \mathrm{ng}$ of purified PCR product added to $1 \mathrm{mM}$ of primer and $2 \mu \mathrm{L}$ of ET mixture for sequencing kit (ET-DYEnamic Dye Terminator Sequencing Kit for Cycle MegaBace, Amersham Bioscience $^{\mathbb{R}}$ ). Ultrapure water was added to make up a final volume of $10 \mu \mathrm{L}$.

Sequencing reaction was performed with 35 cycles of $30 \mathrm{~s}$ at $94{ }^{\circ} \mathrm{C}, 15 \mathrm{~s}$ at $50{ }^{\circ} \mathrm{C}$, and $60 \mathrm{~s}$ at $60^{\circ} \mathrm{C}$. After that, fragments were purified by gel filtration on Sephadex ${ }^{\mathrm{TM}}$ G-50 medium (GE ${ }^{\circledR}$ Healthcare) and electrophoresis was carried out on an automated DNA sequencer model MegaBACE1000 (Amersham Biosciences $\left.^{\circledR}\right)$ [16].

\section{Phylogenetic analysis}

The quality of sequence fragments obtained was checked by Phred software [17]. Sequence fragments were compared on BLASTn (ftp://ftp.ncbi.nlm.nih.gov/ blast/) and sequences of reference were obtained from NCBI database (www.ncbi. nlm.nih.gov). Alignments using the obtained sequences and reference sequences were obtained using the PRANK software [18]. Maximum likelihood trees were set using the program GARLI 2.0 [19]. Bootstrap analyses were performed using 1,000 replicates by DendroPy version 3.8.1 software [20].

\section{Diversity and ecological associations}

Fungal diversity was evaluated by the Shannon index, which generally ranges between 1 and 3.5, equivalent to common and rare species [21]. It was also 
estimated by the Simpson index considering values between 0 and 1 [22], and it was stable with smaller sample sizes. This estimative was obtained for all isolated fungi using PAST software [23].

\section{Results}

\section{Isolation and morphological classification}

About 27 different fungi morphotypes were obtained from leaves of two maize plant lineages (L1 and L2). Out of all the morphotypes, 15 were isolated from L1 and 12 from L2. In both lineages, it was not possible to isolate fungi considered as etiologic agents of diseases (C. zeae-maydis and E. turcicum). Reproductive structures were observed in $92.6 \%$ of fungi (Figure 1).

From L1, 86.7\% of fungi belonged to Dothideomycetes (Phoma, Epicoccum, Cladosporium, Bipolaris/Cochliobolus, and Alternaria) and $13.3 \%$ to Sordariomycetes (Diaporthe/Phomopsis sp. and Nigrospora sp.). Proportion ratio was opposite for L2, with $25.0 \%$ of Dothideomycetes (Epicoccum and

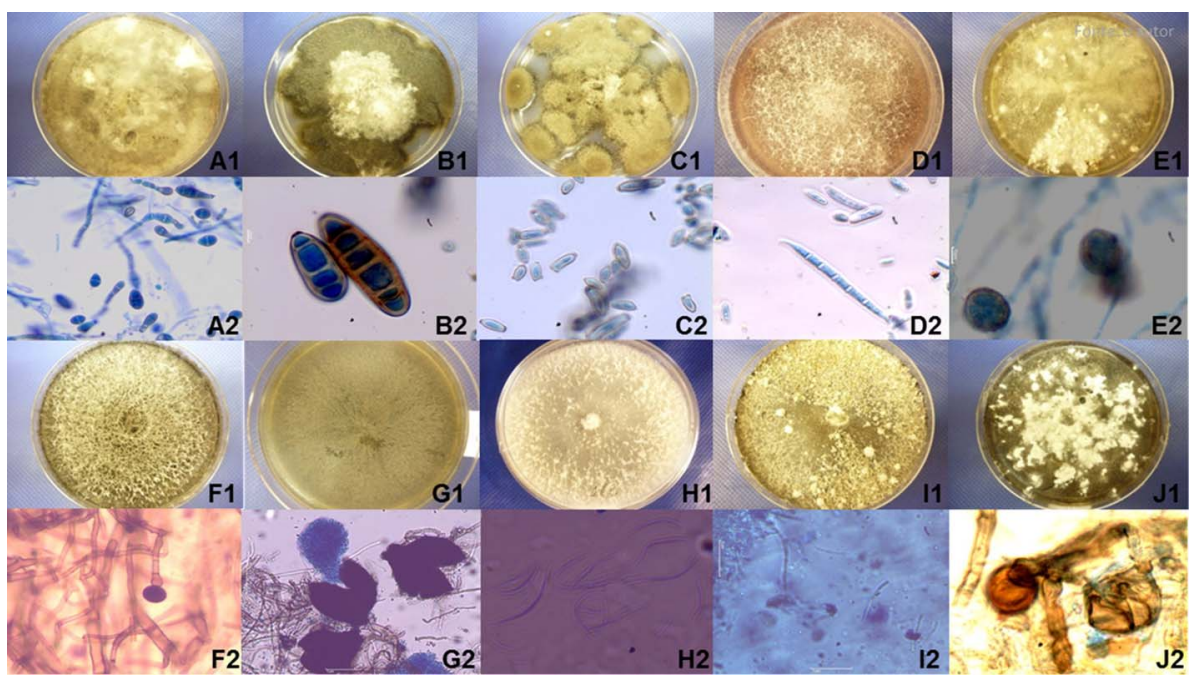

Figure 1. Morphological characterization of isolated fungi grown in PDA medium. A1 and A2: Alternaria sp. (LGMF1021); B1 and B2: Bipolaris sp. (LGMF1013); C1 and C2: Cladosporium sp. (LGMF1020); D1 and D2: Fusarium sp. CGF (LGMF1243); E1, E2, J1, and J2 Phoma/ Epicoccum sp. (LGMF1042, LGMF1016); F1 and F2: Nigrospora sp. (LGMF1017); G1 and G2: Phoma sp. (LGMF1051); H1 and H2: Phomopsis sp. (LGMF1026); I1 and I2: Diaporthe/Phomopsis sp. (LGMF1245) 
Pleosporales) and $75.0 \%$ of Sordariomycetes (Gibberella, Fusarium, Diaporthel Phomopsis sp., and Nigrospora sp.) (Table I and Figure 2).

Fungal identification by ITS1-5.8S-ITS2 rDNA analysis

Using BLASTn tool, it was possible to verify the percentage of similarity comparing obtained sequences and sequences from reference strains. Sequences of 417-544 bp length were used. LGMF1041 had the lowest similarity percentage (94\%) and the other showed 96\%-100\% (Table I).

Phylogenetic tree was built using the maximum likelihood model (Figure 3). Among these fungi, one (LGMF1041) was set into Pleosporales order (group 6) since its genus classification was not clear, and it was genetically related to Ochrocladosporium and Leptosphaeria. It was possible to define the genus of seven fungi: LGMF1026, LGMF1040, and LGMF1054 belong to Diaporthe/Phomopsis sp. (group 4); LGMF1020 belong to Cladosporium (group 3) and LGMF1017, LGMF1038, and LGMF1039 belong to Nigrospora sp. (group 2). Seven individuals were placed in groups of three complex species: Alternaria alternata complex (AAC) (LGMF1018 and LGMF1021), with 99\% of support (group 8); Fusarium graminearum complex (FGC) (LGMF1036 and LGMF1037) and Gibberella fujikuroi complex (GFC) (LGMF1049, and LGMF1050 LGMF1053) with $93 \%$ and $82 \%$ of support, respectively (group 1) (Figure 3).

Isolated LGMF1013 and LGMF1022 strongly matched to Bipolaris zeicola species (synonymy: Cochliobolus carbonum), with 98\% of support (group 7). Both showed $99 \%$ of similarity with B. zeicola ATCC 48129 (Table I). LGMF1014, LGMF1016, LGMF1019, LGMF1024, LGMF1025 LGMF1042, and LGMF1043 were placed in E. nigrum group. All of them had $99 \%$ of similarity with E. nigrum CBS 115825 except LGMB1042, which was 98\% (group 5).

LGMF1015, LGMF1023, and LGMF1051 were classified into Phoma sorghina group. The isolates LGMF1023 and LGMF1051 are the most similar to P. sorghina PD88/549 (99\%), and the other one is $96 \%$ (Table I).

\section{Diversity and ecological associations}

The most representative order was Pleosporales, including 15 morphotypes (55.5\%), 12 from L1 and 3 from L2. It was followed by the Hypocreales order $(18.5 \%)$ with five fungi, all of them from L2. Diaporthales and Trichosphaerales comprehended three morphotypes each, one from L1 and two from L2. Finally, 


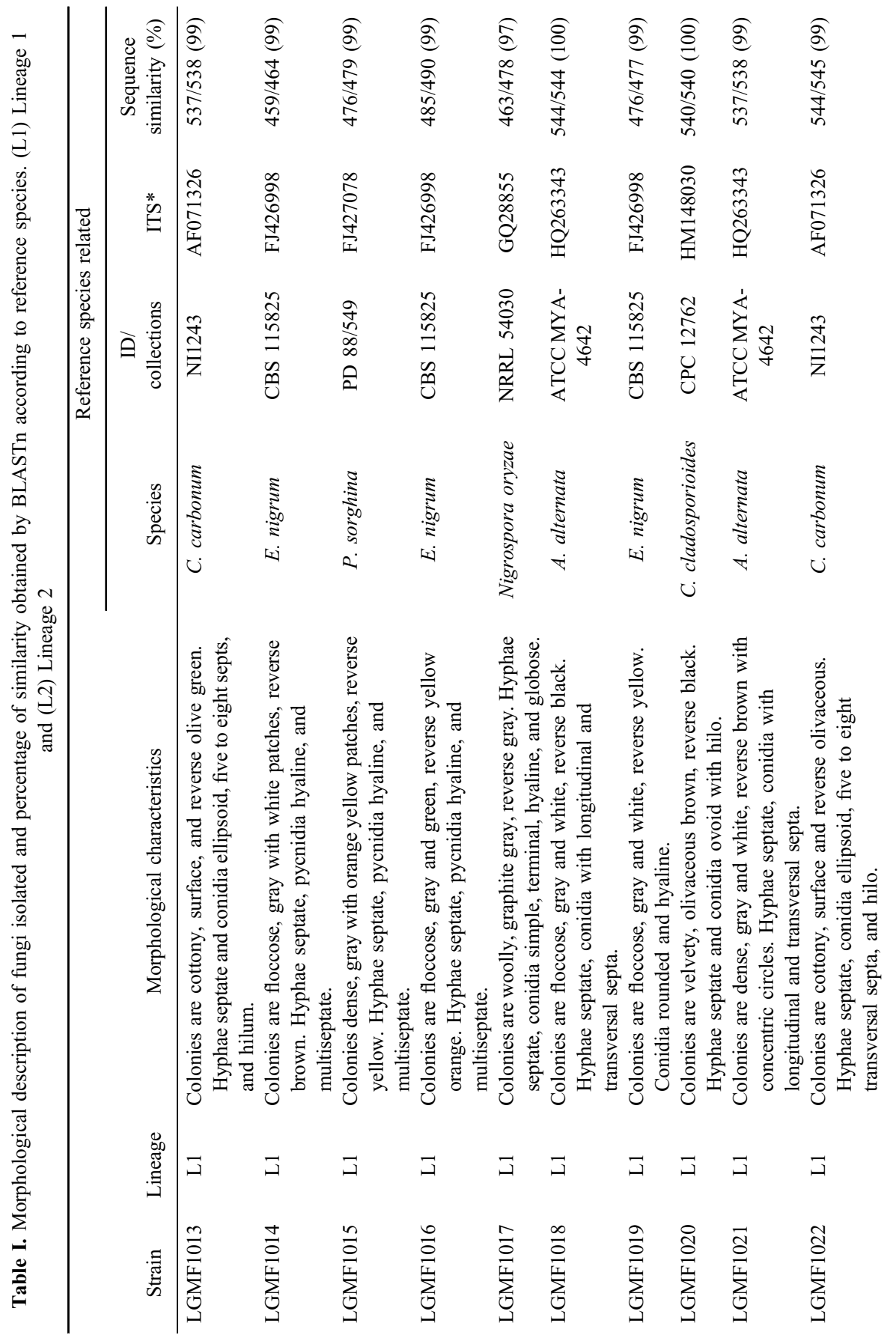




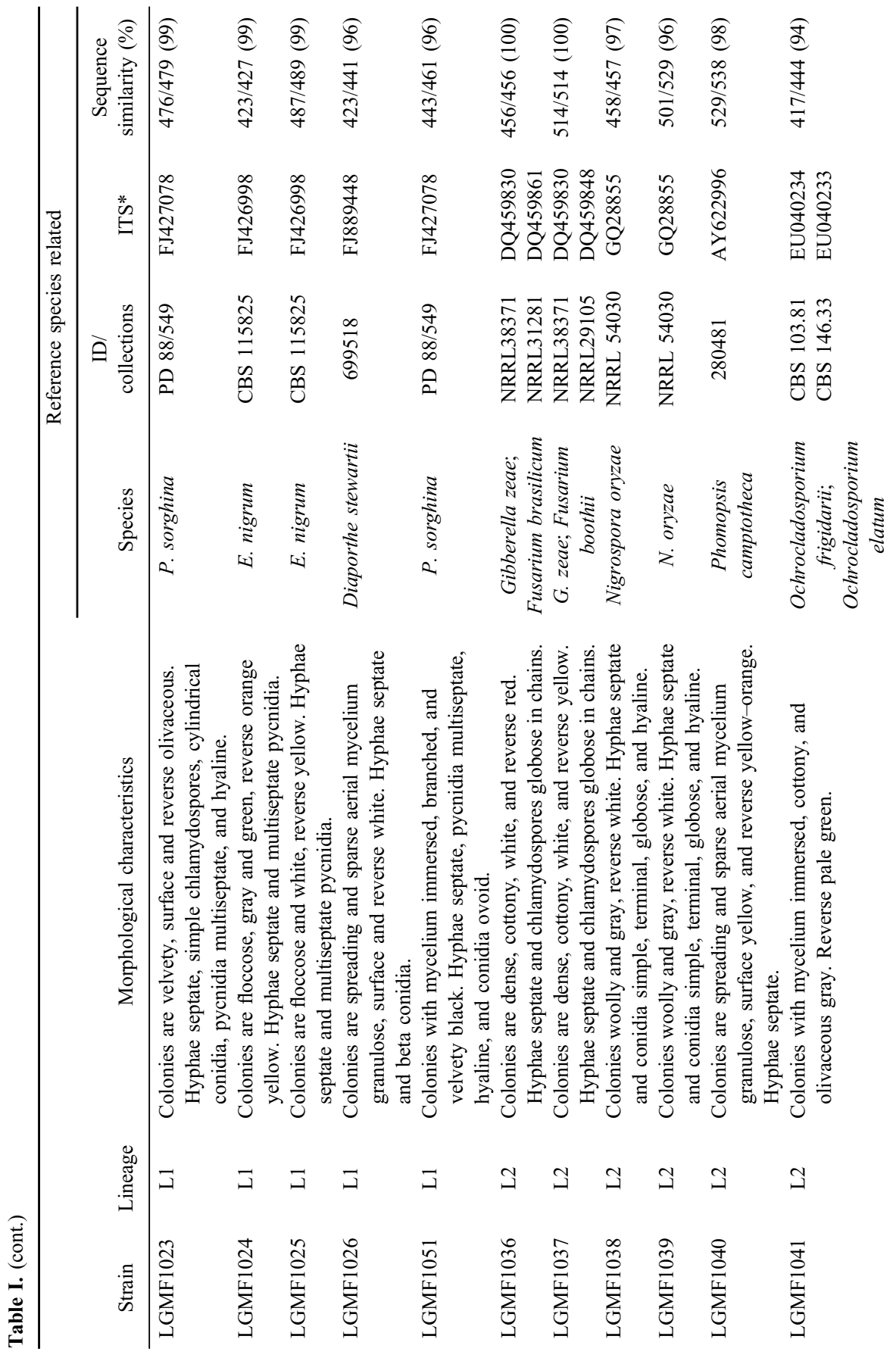




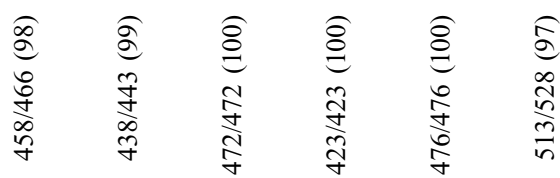

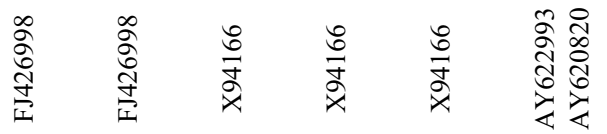

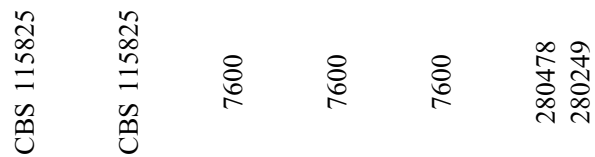

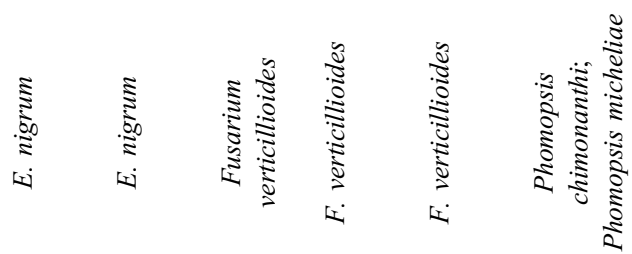

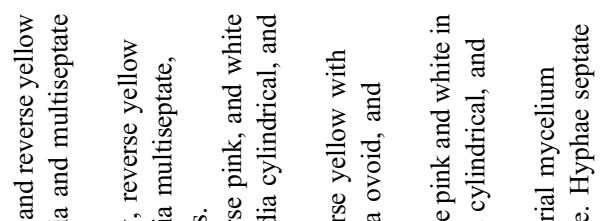

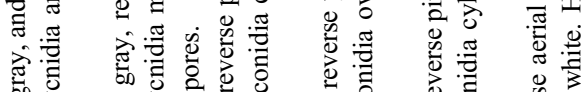

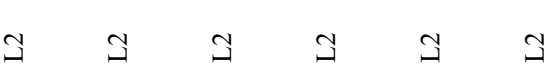

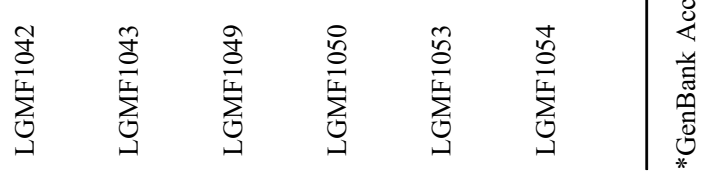




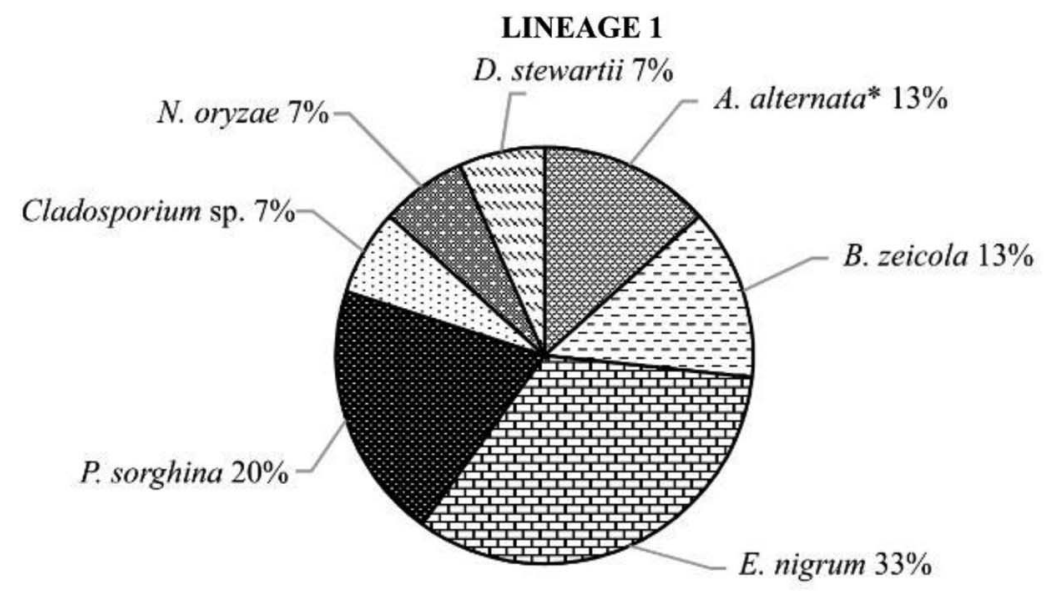

LINEAGE 2

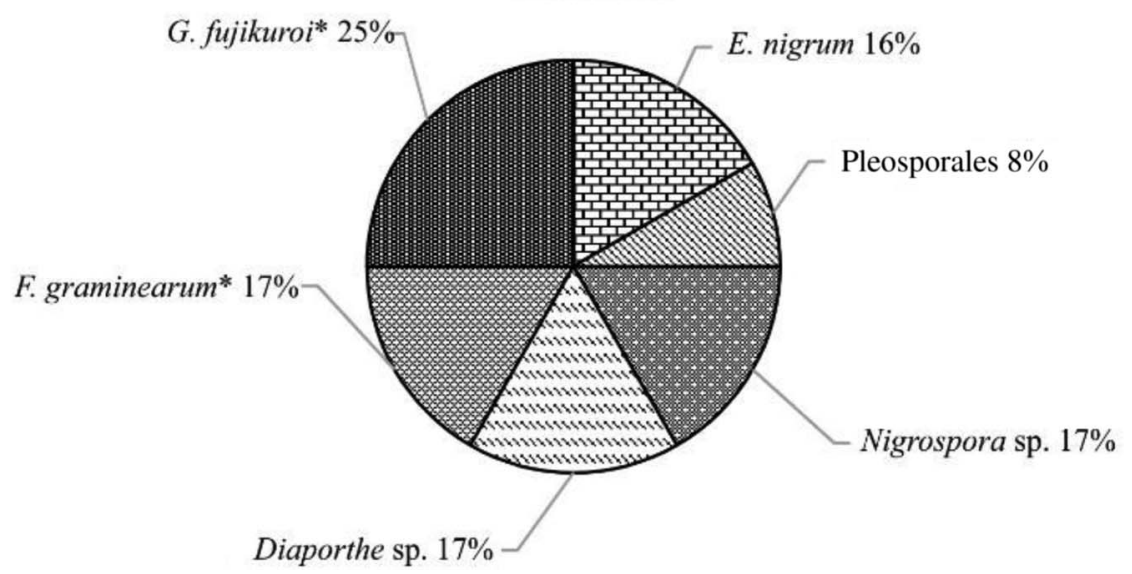

Figure 2. Fungi genera distribution in two lineages of maize according to morphological characterization. *refers to species complex

Capnodiales was the least represented order, with just one morphotype isolated from L1 (Figure 3).

Predominant genera in L1 and L2 are, respectively, Epicoccum (33\%) and Fusarium (anamorfo - Gibberella) (42\%). L1 totaled six genera and L2 totaled four (Table I and Figure 3).

Shannon-Wiener and Simpson diversity index were $\mathrm{H}^{\prime}=2.067$ and $1-\mathrm{D}=0.855$. Comparing $\mathrm{L} 1$ and $\mathrm{L} 2$ diversity: $\left(\mathrm{H}^{\prime}=1.767\right.$ and $\left.1-\mathrm{D}=0.80\right)$ for $\mathrm{L} 1$ and $\left(\mathrm{H}^{\prime}=1.594\right.$ and $\left.1-\mathrm{D}=0.7934\right)$ for $\mathrm{L} 2$. 


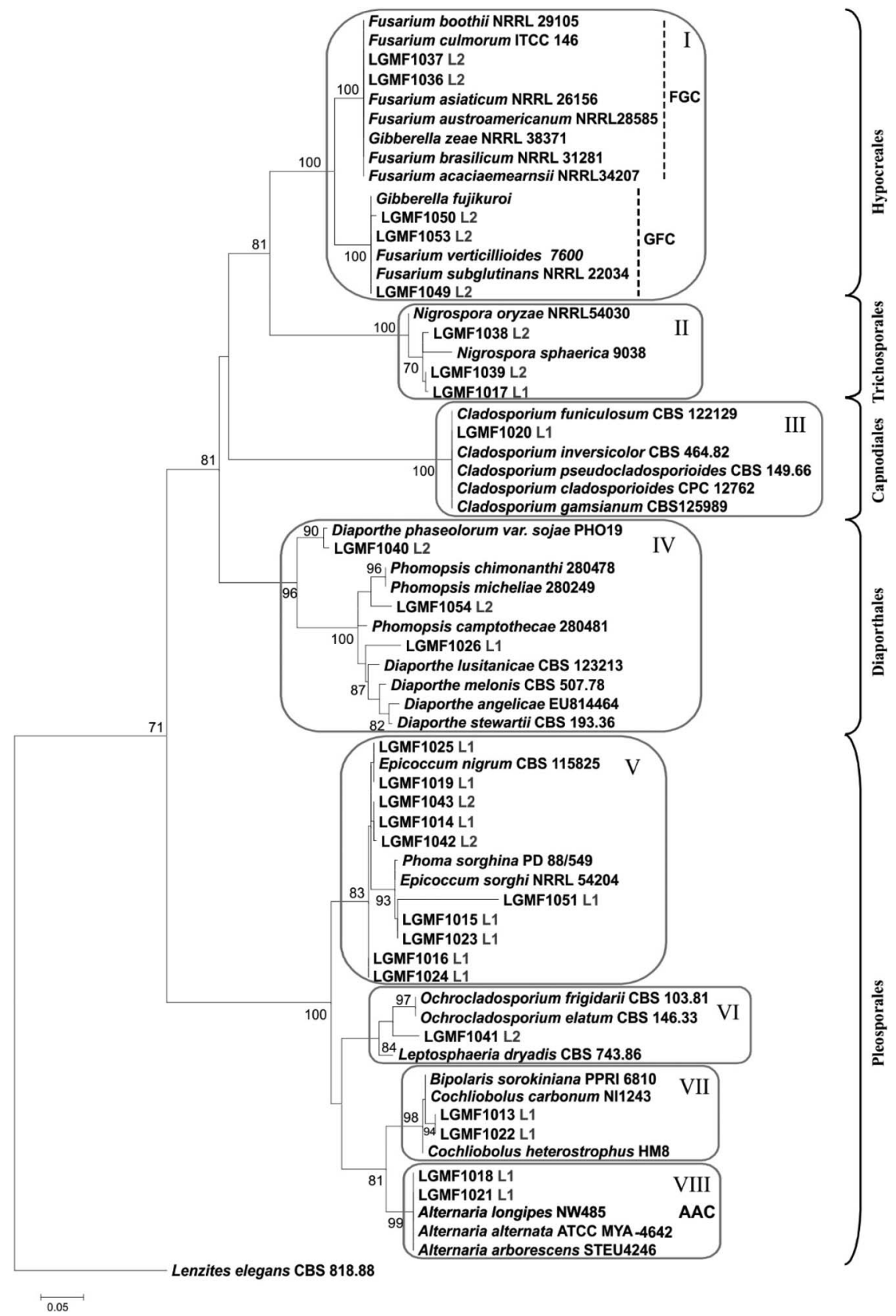

Figure 3. Phylogenetic tree based on ITS1-5.8S-ITS2 sequences concerning fungi isolated in this study and sequences from reference strains obtained from NCBI. Eight groups were set using fragments of $545 \mathrm{bp}$ length. Data were generated using maximum likelihood model and Lenzites elegans CBS 818.88 as outgroup. L1 and L2: lineages of maize; AAC, Alternaria alternata complex; GFC, Gibberella fujikuroi complex; FGC, Fusarium graminearum complex 


\section{Discussion}

Usually, fungi identification involves the analysis of morphological characteristics by microcultures and phylogenetic analysis. These techniques provide more accurate identification results [24]. In this context, ITS1-5.8S-ITS2 region of rDNA sequencing analysis has been successfully used for some taxa. However, some fungi isolated in this study belong to species whose sequences are not available in scientific databases. It may be not an effective identification tool at the species level, but it is very efficient for identification at genus level [25].

We analyzed the fungi diversity (Shannon-Wiener and Simpson diversity index) from two different lineages of maize plant cultivated in the same area. L1 is more diverse in morphotypes, more than half (53\%) belongs to Phoma/Epicocum group. This same group appears in a minor amount L2 (17\%). While members of the group Fusarium (FGC and GFC) together account for $42 \%$ of the total morphotypes in L2 and surprisingly are not present in L1. These differences may be related to the plant genotype and the types of damage caused by diseases present on the leaves, because the two lineages were grown at the same time on the same type of soil and environment.

In this study, the most abundant species was E. nigrum (Punith., MC and CM Leach Tulloch 1972), ubiquitous fungus that can present an endophytic lifestyle [26], but is also associated with the primary decomposition of plant tissues [27]. E. nigrum has been used as a biological control agent on peaches and nectarines orchards against Monilinia spp. [28] and Pythium cotton [29].

In addition to E. nigrum, two more genera, Diaporthe/Phomopsis sp. and Nigrospora sp., were found in both L1 and L2. Nigrospora genus has not enough sequences deposited in databases like Genbank, where only two species were found with described sequences (http://www.ncbi.nlm.nih.gov). This fact hinders the consolidation of phylogenetic studies about this genus. Some other groups require multigene analysis in order to clearly distinguish their taxonomic position, such Diaporthe/Phomopsis [3]. In this study, those funguses appear as endophytic, colonizing both lineages of maize plants. Other group of fungi requires multigene analysis to clarify their taxonomy, such as Cladosporium genus [30], found in L1, and especially for complex species such as Cladosporium cladosporioides [12].

Furthermore, we found P. sorghina, B. zeicola, and AACs in L1. It has been reported that specimens of $P$. sorghina are morphological and phylogenetically diverse and probably represent multiple species [31]. This is also the agent of Phaeosphaeria leaf spot in maize, along with Phaeosphaeria maydis [32]. Bipolaris spot caused by B. zeicola is common in Brazil with low to medium severity. Currently, in some areas of the Midwest and Northeast, an outbreak of considerably severe diseases is taking place in susceptible cultivars [33]. It is 
possible to differentiate Cochliobolus heterostrophus, C. carbonum, Cochliobolus victoriae, Burkholderia sacchari, and Bipolaris sorghicola species by ITS region sequencing to corroborate our data [34].

AAC is a group with few data on morphological and molecular characteristics, which would allow a clear discrimination between taxa [35]. It is not possible to discern members of this group by the analyses of major mitochondrial ribosomal sub-unit, beta-tubulin, actin, calmodulin, chitin synthase, elongation factor alpha, and 1,3,8-trihydroxynaphthalene reductase [36]. Consequently, it is still unclear how this branch should be phylogenetically classified [35]. A. alternata is commonly associated with plants for food production, and may cause fruit deterioration during shipping and storage, for example. This species is responsible for the production of a variety of mycotoxins, like alternariol; alternariol monomethyl ether; altenuene; altertoxins I, II, and III; and L-Tenuazonic acid [10]. Fusarium (anamorfo: Gibberella) genus, despite being extremely widespread in at least $80 \%$ of cultivated plants, is associated with at least one disease caused by one of its species [37] and was found only in L2. Asymptomatic maize plants, showing stalk rot, are infected by Fusarium moniliforme and may decrease up to $50 \%$ of their photosynthetic capacity. This causes reduction of electron transport components and consequently reduces carbohydrate synthesis, which is possibly caused by toxins produced by fungi [38].

Species from FGC can be characterized by morphological structures and ITS1-5.8S-ITS2 rDNA sequencing but sometimes a more accurate identification is needed [39]. Therefore, species determination has been done by multi-gene analysis, considering up to 13 genes discriminating 13 species: Fusarium acacia mearnsii, Fusarium aethiopicum, Fusarium asiaticum, Fusarium austroamericanum, Fusarium boothii, Fusarium brasilicum, Fusarium cortaderia, Fusarium gerlachii, F. graminearum sensu stricto, Fusarium meridionale, Fusarium mesoamericanum, Fusarium ussurianum, and Fusarium vorosii [39]. Members of FGC group cause rotting tip on corn spikes [40]. In addition, F. graminearum and Fusarium culmorum cause stem rot [41]. All FGC species produce trichothecenes type B toxin [39] and zearalonas (F. culmorum and Fusarium cerealis) [42]. Most foliar endophytes species belong to Dothideomycetes and Sordariomycetes classes [43]. This represents over $75 \%$ of the endophytes described, spread from Arctic to Tropics. Their abundance varies depending on the latitude [44], genetic diversity, host genotype, and on how they are acquired from the environment and on the ability of their individuals to co-colonize hosts [11]. All genera of fungi reported in this study have been associated with maize. Some in vegetative tissues such as Cochliobolus, Epicoccum, Phoma, and Diaporthe [45] and other in seeds such as Nigrospora sp., besides fungi already mentioned [46]. Alternaria, Cladosporium, 
and Fusarium are considered soil living fungi, which invade grains at pre- or post-harvest stage and can cause damage in corn before threshing [47]. Epicoccum and Nigrospora sp. grow up in grains near post-harvest or at storage period, altering grain health. Some problems caused by these fungi are loss of weight/ discoloration/necrosis of grains and mycotoxin production, and they are decisive factors for international trade of corn. The presence of mycotoxins, besides being harmful to human and animal health, leads to significant economic losses for farmers [48].

These groups of fungi may also be found in other hosts as medicinal plants [29], trees (Acer truncatum) [25]. These reports corroborate with the pogo stick hypothesis, postulating that host-specific fungal pathogens frequently show the ability to colonize non-host tissue, enabling them to disperse further, in an attempt to find the host on which they are pathogenic $[3,49]$.

Abundance, diversity, and species composition of endophytes are influenced by microhabitat, microclimatic conditions [50], and dynamics of horizontal and vertical transmission of microorganisms [26]. Horizontal transfer may be detected by studying seedlings cultivated under sterile conditions [51]. Vertical transfer was observed in Fusarium spp. colonizing seeds of cowpea [52]. In addition, host genotype may influence biodiversity of endophytic fungi and can affect genetic variation of these endophytes [53].

Some endophytes are generalists, being able to infect a wide range of hosts, while others are specialists, limited to one or a few hosts [5]. Some species have been described as either non-harmful exclusive endophytes, or phytopathogenic. However, studies suggest that a significant number of fungi may represent multiple ecological roles. Fungal pathogens may inhabit different hosts at different stages of life, as distinct modes of interaction [54]. Endophytes can take place when leaves reach senescence [55]. For example, Fusarium verticillioides is commonly isolated from maize plants, even in the absence of visible symptoms. In this condition, as latent pathogens (endophyte transitory), it can contribute to mycotoxins accumulation [56]. Plants may develop typical disease symptoms only when they go through biotic and abiotic stress situations [57]. In this same context, Chaetomium globosum is known as endophyte, saprophytic, or pathogen [43]. Therefore, for some species, the distinction between endophytic, phytopathogenic, and opportunistic microorganisms is purely theoretical. There is a slight threshold dividing them, so it is difficult to establish the limits to separate each category [58].

In this study, it is possible, by molecular phylogeny analysis of the ITS1-5.8S-ITS2 region of rDNA, to identify saprophytic, phytopathogenic, and micotoxic fungal species co-inhabiting leaf tissue of maize plants considering two homozygous genotypes (lineages). It also indicated the necessity to expand studies 
about endophytic microbiota associated with this culture. It is essential to better understand the dynamics and risks associated with changes in saprophytic condition that can enable a fungus manifestation as phytopathological, a phenomenon usually triggered by environmental fluctuations.

\section{Conflict of Interest}

The authors declare that they have no conflict of interest.

\section{References}

1. Bono, J., Rodrigues, A., Mauad, M., Albuquerque, J., Yamamoto, C., Chermouth, K., Freitas, M.: Modo de aplicação de fertilizantes nitrogenados na qualidade fisiológica de sementes de milho [Application of nitrogen fertilizers and physiological quality of corn seeds]. Rev Agrarian 1, 91-102 (2008).

2. Juniper, B. E.: The leaf from the inside and the outside: A microbe's perspective. In Andrews, J. H, Hirano S. S. (eds): Microbial Ecology of Leaves. Springer-Verlag, New York, 1991, pp. 21-42.

3. Gomes, R. R., Glienke, C., Videira, S. I. R., Lombard, L., Groenewald, J. Z., Crous, P. W.: Diaporthe: A genus of endophytic, saprobic and plant pathogenic fungi. Persoonia 31, 1-41 (2013).

4. Promputtha, I., Lumyong, S., Dhanasekaran, V., Mckenzie, E. H. C., Hyde, K. D., Jeewon, R.: A phylogenetic evaluation of whether endophytes become saprotrophs at host senescence. Microb Ecol 53, 579-590 (2007).

5. Zabalgogeazcoa, I.: Fungal endophytes and their interaction with plant pathogens. Span J Agric Res 6, 138-146 (2008).

6. Hyde, K. D., Soytong, K.: The fungal endophyte dilemma? Fungal Divers 33, 63-173 (2008).

7. Shurtleff, M. C.: Compendium of Corn Diseases. American Phytopathological Society, St. Paul, USA, 1980.

8. Reis, E. M., Casa, R. T., Bresolim, A. C. R.: Manual de Diagnose e Controle de Doenças de Milho [Diagnosis Manual and Corn Diseases Control]. Graphel, Lages, 2004.

9. Tanaka, M. A. S., Maeda, J. A., Ihde, A., Plazas, Z.: Fungi associated to corn seeds under storage conditions. Sci Agri 58, 501-508 (2001).

10. Scott, P. M.: Analysis of agricultural commodities and foods for Alternaria mycotoxins. J AOAC Int 84, 1809-1817 (2001).

11. Herre, E. A., Knowlton, N., Mueller, U. G., Rehner, S. A.: The evolution of mutualisms: Exploring the paths between conflict and cooperation. Trends Ecol Evolut 14, 49-53 (1999).

12. Bensch, K., Groenewald, J. Z., Dijksterhuis, J., Starink-Willemse, M., Andersen, B., Summerell, B. A., Shin, H.-D., Dugan, F. M., Schroers, H.-J., Braun, U., Crous, P. W.: Species and ecological diversity within the Cladosporium cladosporioides complex (Davidiellaceae Capnodiales). Stud Mycol 67, 1-94 (2010). 
13. De Hoog, G. S., Gerrits Van Den Ende, A. H. G.: Molecular diagnostics of clinical strains of filamentous Basidiomycetes. Mycoses 41, 183-189 (1998).

14. White, T. J., Bruns, T., Lee, S., Taylor, J.: Amplification and direct sequencing of fungal ribosomal RNA genes for phylogenetics. In Innis, M. A., Gelfand, D. H., Sninsky, J. J., White, T. J. (eds): PC Protocols: A Guide to Methods and Applications. Academic, San Diego, 1990, pp. 315-322.

15. Menna, P., Hungria, M., Barcellosa, F. G., Bangele, E. V., Hessf, P. N., Martinez-Romero, E.: Molecular phylogeny based on the 16S rRNA gene of elite rhizobial strains used in Brazilian commercial inoculants. Syst Appl Microbiol 29, 315-332 (2006).

16. Szilagyi-Zecchin, V. J., Ikeda, A. C., Hungria, M., Adamoski, D., Kava-Cordeiro, V., Glienke, C., Galli-Terasawa, L. V.: Identification and characterization of endophytic bacteria from corn (Zea mays L.) roots with biotechnological potential in agriculture. AMB Express 4, 1-9 (2014).

17. Ewing, B., Hillier, L., Wendl, M. C., Green, P.: Basecalling of automated sequencer traces using phred I accuracy assessment. Gen Res 8, 175-185 (1998).

18. Löytynoja, A., Goldman, D.: webPRANK: A phylogenyaware multiple sequence aligner with interactive alignment browser. BMC Bioinformatics 11, 579 (2010).

19. Zwickl, D. J.: Genetic algorithm approaches for the phylogenetic analysis of large biological sequence datasets under the maximum likelihood criterion. $\mathrm{PhD}$ dissertation, The University of Texas at Austin, 2006.

20. Sukumaran, J., Holder, M. T.: DendroPy: A Python library for phylogenetic computing. Bioinformatics 26, 1569-1571 (2010).

21. Shannon, C. E., Weaver, W.: The Mathematical Theory of Communication. University of Illinois Press, Urban, 1949.

22. Simpson, E. H.: Measurement of species diversity. Nature 163, 688 (1949).

23. Hammer, Ø., Harper, D. A. T., Ryan, P. D.: Past: Paleontological statistics software package for education and data analysis. Paleontol Electron 4, 4-9 (2001).

24. Bernardi-Wenzel, J., García, A., Filho-Celso, J. R., Prioli, A. J., Pamphile, J. A.: Evaluation of foliar fungal endophyte diversity and colonization of medicinal plant Luehea divaricata (Martius et Zuccarini). Biol Res 43, 375-384 (2010).

25. Sun, X., Guo, L. D., Hyde, K. D.: Community composition of endophytic fungi in Acer truncatum and their role in decomposition. Fungal Divers 47, 85-95 (2011).

26. Arnold, A. E.: Understanding the diversity of foliar fungal endophytes: Progress challenges and frontiers. Fungal Biol Rev 21, 51-66 (2007).

27. Mims, C. W., Richardson, E. A.: Ultrastructure of sporodochium and conidium development in the anamorphic fungus Epicoccum nigrum. Can J Bot 83, 1354-1363 (2005).

28. de Cal, M. A., Larena, I., Liñán, M., Torres, R., Lamarca, N., Usall, J., Domenichini, P., Bellini, A., de Eribe, X. O., Melgarejo, P.: Population dynamics of Epicoccum nigrum a biocontrol agent against brown rot in stone fruit. J Appl Microbiol 106, 592-605 (2009).

29. Hashem, M., Ali, E. H.: Epicoccum nigrum as biocontrol agent of Pythium damping-off and root rot of cotton seedlings. Arch Phytopathol Plant Prot 37, 283-297 (2004).

30. Schubert, K., Greslebin, A., Groenewald, J. Z., Crous, P. W.: New foliicolous species of Cladosporium from South America. Persoonia 22, 111-122 (2009).

31. Aveskamp, M. M., De Gruyter, J., Woudenberg, J. H. C., Verkley, G. J. M., Crous, P. W.: Highlights of the Didymellaceae: A polyphasic approach to characterise Phoma and related pleosporalean genera. Stud Mycol 65, 1-60 (2010). 
32. Amaral, A. L., Carli, M. L., Barbosa Neto, J. F., Dal Soglio, F. K.: Phoma sorghina a new pathogen associated with Phaeosphaeria leaf spot on maize in Brazil. New Dis Rep 8, 26 (2003).

33. Costa, R. V., Casela, C. R., Cota, L. V.: Embrapa Milho e Sorgo Sistemas de Produção 1, Cultivo do Milho - Doenças [Embrapa Maize and Sorghum, Production Systems 1, Growing Corn - Diseases], $6^{\text {th }}$ Edition, 2010. Available from http://www.cnpms. embrapabr/publicacoes/milho_6_ed/doencas.htm. Accessed 15 January 2011.

34. Berbee, M. L.: Loculoascomycete origins and evolution of filamentous Ascomycete morphology based on 18S gene sequence data. Mol Biol Evol 13, 462-470 (1996).

35. Andrew, M., Peever, T. L., Pryor, B. M.: An expanded multilocus phylogeny does not resolve morphological species within the small spored Alternaria species complex. Mycologia 101, 95-109 (2009).

36. Peever, T. L., Su, G., Carpenter-Boggs, L., Timmer, L. W.: Molecular systematics of citrusassociated Alternaria species. Mycologia 96, 119-134 (2004).

37. Leslie, J. F., Summerell, B. A.: The Fusarium Laboratory Manual. Blackwell Publishing Ltd., Iowa, 2006.

38. Pinto, L. S. R. C., Azevedo, J. L., Pereira, J. O., Vierira, M. L. C., Labate, C. A.: Symptomless infection of banana and maize by endophytic fungi impairs photosynthetic efficiency. New Phytol 147, 609-615 (2000).

39. O'Donnell, K., Ward, T. J., Aberra, D., Kistler, H. C., Aoki, T., Orwig, N., Kimura, M., Bjornstad, A., Klemsda, L. S. S.: Multilocus genotyping and molecular phylogenetics resolve a novel head blight pathogen within the Fusarium graminearum species complex from Ethiopia. Fungal Gen Biol 45, 1514-1522 (2008).

40. Sampietro, D. A., Díaz, C. G., Gonzalez, V., Vattuone, M. A., Ploper, L. D., Catalan, C. A. N., Ward, T. J.: Species diversity and toxigenic potential of Fusarium graminearum complex isolates from maize fields in northwest Argentina. Int J Food Microbiol 145, 359364 (2011).

41. Pronczuk, M., Pronczuk, S., Messyasz, M.: Pathogenicity of Fusarium spp. contributing to the stalk rot of maize in Poland. Mycotoxin Res 7, 97-101 (1991).

42. IARC Monographs on the Evaluation of Carcinogenic risks to Humans: Some naturally occurring substances: Food items and constituents heterocyclic aromatic amines and mycotoxins. International Agency for Research on Cancer, Lyon, 1993.

43. Arnold, A. E., Miadlikowska, J., Higgins, K. L., Sarvate, S. D., Gugger, P., Way, A., Hofstetter, V., Kauff, F., Lutzoni, F.: A phylogenetic estimation of trophic transition networks for ascomycetous fungi: Are lichens cradles of symbiotrophic fungal diversification? Syst Biol 58, 283-297 (2009).

44. Arnold, A. E., Lutzoni, F.: Diversity and host range of foliar fungal endophytes: Are tropical leaves biodiversity hotspots? Ecology 88, 541-549 (2007).

45. Pan, J. H., Jones, E. B. G., She, Z. G., Pang, J. Y., Lin, Y. C.: Review of bioactive compounds from fungi in the South China. Sea Bot Mar 51, 179-190 (2008).

46. Niaz, I., Dawar, S.: Detection of seed borne mycoflora in maize (Zea mays L.). Pakistan J Bot 41, 443-451 (2009).

47. Watson, S. A., Ramstad, P. E.: Corn: Chemistry and Technology. American Association of Cereal Chemist, St. Paul, 1987.

48. Chassy, B. M.: Food safety risks and consumer health. New Biotechnol 27, 534-544 (2010). 
49. Crous, P. W., Groenewald, J. Z.: Hosts, species and genotypes: Opinions versus data. Australas Plant Path 34, 463-470 (2005).

50. Arnold, A. E., Herre, E. A.: Canopy cover and leaf age affect colonization by tropical fungal endophytes: Ecological pattern and process in Theobroma cacao (Malvaceae). Mycologia 95, 388-398 (2003).

51. Arnold, A. E., Engelbrecht, B. M. J.: Fungal endophytes double minimum leaf conductance in seedlings of a tropical tree. J Trop Ecol 23, 369-372 (2007).

52. Rodrigues, A. A. C., Menezes, M.: Identification and pathogenic characterization of endophytic Fusarium species from cowpea seeds. Mycopathol 159, 79-85 (2005).

53. Ahlholm, J. U., Helander, M., Henriksson, J., Metzler, M., Saikkonen, K.: Environmental conditions and host genotype direct genetic diversity of Venturia ditricha a fungal endophyte of birch trees. Evolution 56, 1566-1573 (2002).

54. Agrios, G. N.: Plant Pathology, $5^{\text {th }}$ Edition. Elsevier Academic Press, London, 2005.

55. Korkama-Rajala, T., Müeller, M. M., Pennanen, T.: Decomposition and fungi of needle litter from slow- and fast-growing Norway spruce (Picea abies) clones. Microbial Ecol 56, 76-89 (2008).

56. Bacon, C. W., Hinton, D. M.: Symptomless endophytic colonization of maize by Fusarium moniliforme. Can J Bot 74, 1195-1202 (1996).

57. Bottalico, A., Logrieco, A., Visconti, A.: Fusarium species and their mycotoxins in infected corn in Italy. Mycopathol 107, 85-92 (1989).

58. Azevedo, J. L., Júnior, W. M., Pereira, J. O., Araújo, W. L.: Endophytic microorganisms: A review on insect control and recent advances on tropical plants. Environ Biotechnol 3, 40-65 (2000). 